BULLETIN Bulletin hispanique

HISPANIQUE Université Michel de Montaigne Bordeaux

119-1 | 2017

Autorité et pouvoir dans le théâtre du Siècle d'Or

\title{
El poder de la palabra, el silencio y la invisibilidad en las muestras de autoridad del teatro prebarroco
} el Códice de Autos Viejos

Delia Gavela García

\section{OpenEdition}

\section{Journals}

Edición electrónica

URL: http://journals.openedition.org/bulletinhispanique/4840

DOI: 10.4000/bulletinhispanique.4840

ISBN: 979-10-300-0142-6

ISSN: 1775-3821

\section{Editor}

Presses universitaires de Bordeaux

\section{Edición impresa}

Fecha de publicación: 15 junio 2017

Paginación: 173-186

ISBN: 979-10-300-0141-9

ISSN: 0007-4640

\section{Referencia electrónica}

Delia Gavela García, «El poder de la palabra, el silencio y la invisibilidad en las muestras de autoridad del teatro prebarroco », Bulletin hispanique [En línea], 119-1 | 2017, Publicado el 17 junio 2020,

consultado el 11 septiembre 2020. URL : http://journals.openedition.org/bulletinhispanique/4840 ;

DOI : https://doi.org/10.4000/bulletinhispanique.4840 


\title{
El poder de la palabra, el silencio y la invisibilidad en las muestras de autoridad del teatro prebarroco: el Códice de Autos Viejos
}

\author{
Delia Gavela García \\ Universidad de La Rioja
}

La critique a souligné le caractère narratif des pièces du Códice de Autos viejos, trait qui définit un théâtre encore immature. Sont ici analysées les fonctions de la parole : elle parvient notamment à rendre présents des personnages absents de la scène, mais aptes néanmoins à exercer leur autorité. Est mis aussi en relief le pouvoir du visuel à travers ces personnages silencieux dont les mouvements sur scène sont plus épurés et plus symboliques qu'on pouvait s'y attendre.

Mots-clés: Códice de Autos viejos, autorité, narrativité, personnages silencieux, personnages invisibles.

Del Códice de Autos Viejos se ha destacado el carácter narrativo de las obras allí recogidas, en consonancia con un teatro que adolece de cierta inmadurez. En este artículo se analizan las funciones que, efectivamente, desempeña la palabra, consiguiendo incluso hacer presentes a personajes que sin pasar por el escenario ejercen su autoridad. Se incide también en el poder de lo visual, a través de figuras silentes, que construyen un movimiento escénico más depurado y simbólico de lo que a priori se podría esperar.

Palabras clave: Códice de Autos viejos, poder, narratividad, personajes silentes, personajes invisibles.

Critics have sometimes highlighted the somewhat narrative characteristics of the plays compiled in the "Códice de Autos Viejos", characteristics that are altogether in keeping with a type of theatre that has not reached full maturity. This article analyses the function of the spoken word that manages to give a certain presence to characters who do not actually step onto the stage, but are nevertheless able to exert their authority. The power of the visual elements of the word are also examined through silent characters, used in order to construct a scenic movement starker and more symbolic than one might have thought initially.

Keywords: Códice de Autos viejos, power, narrativity, silent characters, invisible characters. 
Es de gran gusto la historia; todo ya muy declarado, noten lo representado y quédeles en memoria un caso tan señalado.

Auto del sacreficio de Abraham

$\mathrm{L}$ a condición audiovisual del teatro es incontestable. Más discutible es el porcentaje idóneo de información que debe llegar al receptor a través de la vista o del oído. Acercándonos al corpus que nos ocupa, los estudiosos del Códice de Autos Viejos han destacado el carácter narrativo de las obras allí contenidas, vinculándolo a la inercia de la tradición literaria anterior y a la inmadurez que preside este teatro incipiente ${ }^{1}$. Una escenografía muy básica y unos recursos dramáticos aún limitados parecen hacer recaer el funcionamiento de las obras sobre la palabra, inclinando la balanza hacia el plano oral. No obstante, esa palabra cobra vida gracias a unos personajes que, de forma más o menos verosímil, son capaces de crear un contexto espacio-temporal, a través de su discurso y movimientos sobre un escenario.

Palabra y personaje, estos elementos básicos del teatro me sirven de punto de partida para mostrar, en las próximas páginas, algunos recursos, y su funcionalidad, utilizados por los autores del Códice de Autos Viejos en su intento de dar vida a la historia sagrada -en especial a los caracteres que detentan el poder de forma explícita o sutilmente dramatizada-, al mismo tiempo que construyen unos patrones de creación teatral aún no plenamente conformados. Algunos de ellos apuntan herramientas básicas del teatro posterior y otros desaparecerán o disminuirán en incidencia en la fórmula teatral consolidada del XVII, como se irá comentando. Para llevar a cabo este estudio me he centrado en los autos bíblicos -quedan fuera las farsas, los coloquios y las piezas hagiográficas-, con el fin de tener un material de estudio homogéneo y por ser un objetivo prioritario del proyecto que enmarca este trabajo: La Biblia en el teatro áureo español (I): del Códice de Autos Viejos a Lope de Vega². Utilizo los textos contenidos en la edición de Léo Rouanet ${ }^{3}$.

1. Véase Alfredo Hermenegildo, "Teatralidad y narración en el Códice de Autos Viejos», en Miscelánea filológica dedicada a Alberto Porqueras Mayo, coor. por Lola González Martínez, Lleida, Milenio, 2011, pp. 139-160, en especial las pp. 140-142.

2. En ocasiones resulta difícil establecer los límites, pues hay obras con presencia de personajes bíblicos, pero en las que no se puede identificar un pasaje claro de las Sagradas Escrituras. Dado que esta clasificación ha sido necesaria para la realización de diversas investigaciones en los proyectos que auspicia este trabajo, BITAE I: La Biblia en el teatro áureo español (I): del Códice de Autos Viejos a Lope de Vega (Ref. FFI2010-17870) y BITAE II: Nuevos paradigmas de interpretación teatral: respuestas para una sociedad en conflicto multicultural (ref. FFI201347806-R,) me baso en la selección establecida al tal efecto por Luis González Fernández. En la bibliografía final se incluye el elenco de obras analizadas.

3. Colección de Autos, Farsas, y Coloquios del siglo XVI publicada por Léo Rouanet, BarcelonaMadrid, L'Avenç-Librería de M. Murillo, 1901, 4 vols. 
El carácter de la fuente bíblica, con una frecuente acumulación de sucesos, el deseo de los autores de incluir escenarios múltiples o de abarcar un periodo temporal amplio, sin olvidar la finalidad pedagógica que subyace a ellos, hacen de lo narrativo, a falta de otros medios, un elemento básico de la construcción dramática. Si el lector se acerca con una visión impregnada por el uso de este recurso en el teatro del Siglo de Oro, no se sorprende al encontrárselo cumpliendo la función habitual de contextualización. Se trata, sin duda, de uno de los cometidos básicos de las piezas introductorias, tal como señala Mercedes de los Reyes, las cuales presentan el argumento de forma más o menos explícita o incluso prefigurativa ${ }^{4}$. Ya en la parte principal de las obras, son numerosos los ejemplos de pasajes que recogen los antecedentes necesarios para conocer los sucesos anteriores a lo que se está contemplando en escena, o lo que no se ha querido o podido representar (Aucto de cuando Abrahán se fue a tierra de Canaán, vv. 286-2955; Aucto de cuando Jacob fue huyendo a tierras de Arán, vv. 182-193; Aucto de la lucha de Jacob con el ángel, vv. 81-140; Auto de los desposorios de Ysac (V), vv. 356-370; Auto del sueño de Nabucodonosor (XV), vv. 291-324 y 333-342; Auto del rey Assuero quando ahorcó a Aman, vv. 62-126, etc.), pero también, aunque en menor número, aquellos que ofrecen resúmenes de lo previamente acontecido en el escenario (Aucto del finamiento de Jacob, vv. 107-120; Aucto de los desposorios de Isac (VI), vv. 388-411; Auto del robo de Digna, vv. 226-2386, Auto de los desposorios de Joseph, vv. 631-640, etc.) o de lo que está por venir (Aucto de cuando Abrahan se fue a tierra de Canaán, vv. 1120; Auto del robo de Digna, vv. 304-333, Auto del sueño de Nabucodonosor (XV), vv. 351-407, Aucto del rey Asuero quando desconpuso a Basti, vv. 116-137, Auto de los desposorios de Joseph, vv. 491-510, etc.), uso, este último, más extraño en el teatro posterior y fruto, probablemente, de la influencia del frecuente carácter premonitorio de la fuente bíblica y, en otras ocasiones, del intento de evitar pasajes con sucesos escabrosos o difíciles de representar.

A pesar de lo anterior, llama la atención una utilización reiterada y multifuncional de lo narrativo, a veces concentrado en una misma obra. Tomemos como ejemplo el Auto de los desposorios de Ysac, del que además se incluyen dos versiones. Si repasamos los pasajes relatados que se dan en estas piezas gemelas, aparte de la consabida loa y algunos antecedentes, encontramos, de manera paralela en ambas, que tras presenciar la escena clave, cuando Rebeca

4. Mercedes de los Reyes Peña, El «Códice de autos viejos». Un estudio de historia literaria. Prólogo de Francisco López Estrada, Sevilla, Alfar, 1988. 3 vols. y Códice de autos viejos. Selección, edición, introducción y notas de Miguel Ángel Pérez Priego, Madrid, Castalia, 1988, pp. $927-$ 928.

5. Para facilitar la lectura, cito por el número de verso, siguiendo la edición de Léo Rouanet, op. cit. El número de página que ocupa cada auto puede verse en el listado final, que recoge todas las obras utilizadas.

6. En este caso, y no es una excepción, se narra el relato de lo que se ha visto en el escenario, pero se le añaden los detalles escabrosos que el público no ha llegado a presenciar, pues, aunque ha visto el encuentro entre Dina y Siquen, será a posteri, a través de las palabras del rey, cuando reciba la confirmación de que ha sido violada. 
se comporta de forma caritativa y amable con Eliacer ofreciéndole agua, este mismo personaje, ahora ante su padre y hermano, dice lo siguiente:

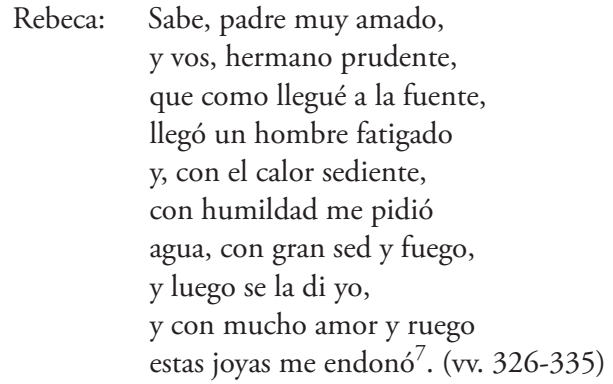

Pocos versos después, es Eliacer quien resume todo lo sucedido hasta ese momento incluyendo, por tercera vez para el espectador, el mismo suceso:

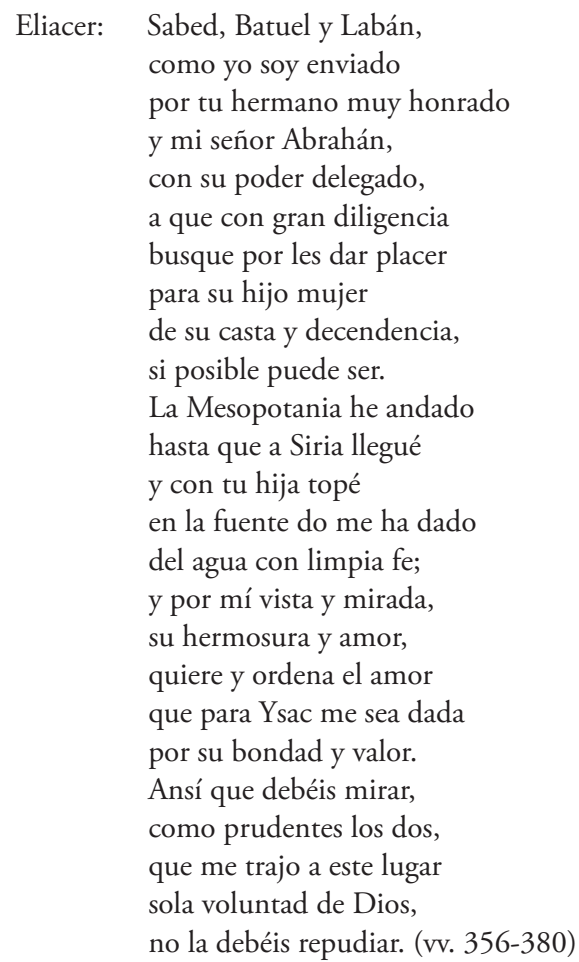

Esta reiteración puede tener una finalidad dramática, relacionada con lo que Hermenegildo llama los ejes interactivos, en torno a los cuales se agrupan los participantes axiales y no axiales, en «un deseo de flexibilizar la monotonía de los parlamentos dirigidos al mismo interlocutor» ${ }^{8}$; además de perseguir

7. En las citas de los textos, modernizo las grafías (excepto cuando tienen valor fonético), la puntuación, la ortografía y la acentuación del editor. Respeto los títulos, tal como aparecen en la edición, pero actualizo también su acentuación.

8. Op. cit., p. 146. Aunque en el patrón resaltado por Hermenegildo está aludiendo a 
la variación espacial que agilice el mensaje mediante el desarrollo «de forma consecutiva en más de un solo lugar» o gracias a la técnica de la «escena múltiple horizontal con dos lugares simultáneamente presentes»" (vid. los vv. 338-352). Aunque también se puede vislumbrar alguna connotación erótica ligada a la tradición, y por tanto comprensible y sugerente para el público, en la presencia de elementos como la fuente o el agua ${ }^{10}$. La ausencia de medios técnicos o la inseguridad de los autores a la hora de establecer cómo se percibirá el movimiento escénico, hacen que se utilice el propio texto para remarcar los avances temporales, los cambios espaciales y las interacciones comunicativas que se dan en cada momento -recursos que seguirán utilzándose en el teatro del XVII- pero esto no obsta para que reconozcamos, también, un intento de dinamizar la representación. Por eso, los espectadores, presencian, en primer lugar, la escena de la fuente; a continuación escuchan cómo Rebeca se la narra a los personajes que no participaron en ella, su padre y hermano, marcando así el cambio espacial y el avance temporal que se ha producido desde ese primer encuentro; seguidamente, y por último, de momento, el otro participante de dicha escena, Eliacer, vuelve a traerla a colación, una vez que Labán lo conduce, en un nuevo cambio espacial realizado a ojos vista del público, a la casa de su padre, Batuel, donde pedirá la mano de Rebeca. Continuando con esta misma obra, encontramos otro ejemplo de didascalia implícita, cuando un correo anuncia a Abraham lo siguiente:

\begin{tabular}{|c|c|}
\hline orahán: & $\begin{array}{l}\text { Sabrás, señor, que Eliacer } \\
\text { queda de aquí una jornada: } \\
\text { trae una dama de alto ser, } \\
\text { la cual Rebeca es llamada, } \\
\text { para ser de Ysac mujer. } \\
\text { Hija es de tu hermano, } \\
\text { esta doncella agraciada, } \\
\text { y ha sido en Siria criada, } \\
\text { y Eliazer, de muy ufano, } \\
\text { os envía esta embajada. (vv. 471-480) }\end{array}$ \\
\hline
\end{tabular}

La llegada de Rebeca, quien hace su aparición cantando, se produce cinco versos más tarde ${ }^{11}$. La narración previa a su aparición vuelve a salvar verbalmente

personajes simultáneamente presentes en el escenario y en el caso que señalo median acotaciones, entradas y salidas de personajes, considero que también se persigue una variación que haga más amena la reiteración.

9. Véase, Mercedes de los Reyes, op. cit., p. 1024-1026 y p. 133 y ss.

10. Agradecemos la sugerencia de esta interpretación al doctor Francisco Peña.

11. Este tipo de anuncios se relaciona con el relato ticoscópico, «relato de acciones que se desarrollan fuera del escenario material», según Ignacio Arellano («Espacios dramáticos en el drama de Calderón», en Calderón: sistema dramático y técnicas escénicas. Actas de las XXIII Jornadas de Teatro Clásico, ed. por Felipe B. Pedraza, Rafael González Cañal y Elena Marcello, Cuenca, Servicio de Publicaciones de la Universidad de castilla-La Mancha, 2001, p. 80). No obstante suele aplicarse el término ticoscopia para sucesos que un personaje está viendo en directo, mientras que, en este caso, el relato es en diferido, ya que, aunque Rebeca aparezca de inmediato, Abrahán comenta lo que vio a una jornada de allí. 
el avance temporal y el cambio espacial que supone el regreso desde Siria y en última instancia esa «jornada» mencionada por el mensajero. Sin embargo habría que atribuirle además a este pasaje una función más efectista, que conjuga muy bien con la costumbre bíblica de la "anunciación», y dramáticamente responde también a un recurso estructural, puesto que implica un cambio escénico, y apelativo, al llamar la atención del auditorio, que es avisado sobre la entrada de un personaje importante. Para terminar con el Auto de los desposorios de Ysac, la primera de las piezas concluye con un largo añadido (vv. 554-713), en el que varios personajes alegóricos narran de nuevo los hechos, a modo de resumen. Sin ánimo de cansar al lector, recojo el suceso de la fuente, relatado en este caso, y por cuarta vez, por alguien tan simbólico como la Moralidad:

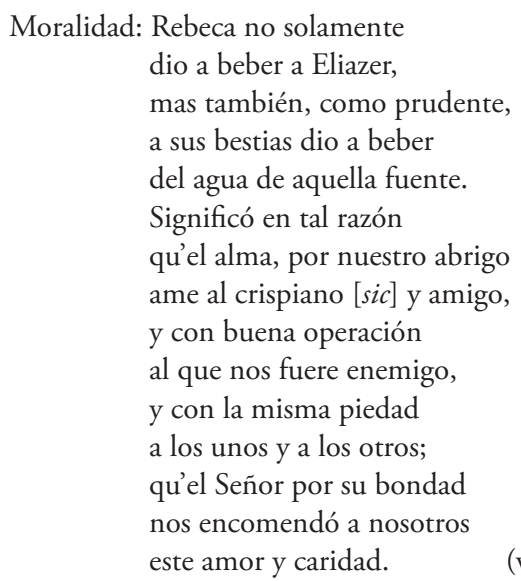

(vv. 614-628)

Mercedes de los Reyes señala en su estudio ${ }^{12}$ que el Códice, a diferencia del teatro de colegio, cuenta con menos personajes alegóricos, debido a que su prioridad es adoctrinar y no moralizar. De acuerdo con este comentario, debo señalar un uso más de la narración en el pasaje que acabo de citar, donde, de manera didáctica, se explicita, por si no hubiera quedado claro en sus tres menciones anteriores, el significado del suceso de la fuente, con una evidente función pedagógica ejercida por el personaje de la Moralidad. Esta reiteración adoctrinante estará mucho menos presente en el teatro veterotestamentario posterior.

Contextualizar, explicar los antecedentes, resaltar los hechos fundamentales, desempeñar una función estructural en los cambios espacio-temporales, marcar las interrelaciones comunicativas, reiterar y hacer explícito el adoctrinamiento..., todas estas funciones llevadas a cabo mediante el uso de la narración tienen un denominador común -y con esto retomo la idea inicial- que es el que confiere sentido dramático a este género, la deixis en phantasma ${ }^{13}$, aunque sería

12. Op. cit., p. 918.

13. Término de Bühler que Arellano define como «Proyecciones de la fantasía constructiva, creando mediante los demostrativos aquello que el espectador debe ver con los ojos de la imaginación: la deixis en phantasma es la que funciona en el decorado verbal», Estructuras 
más preciso en nuestro caso narratio ad fantasma. Siguiendo por ese camino, de «fantasmas» voy a tratar a continuación, pues, atendiendo a una línea de investigación iniciada para el Códice por el profesor Luis González Fernández ${ }^{14}$, quien generosamente me puso sobre la pista, quiero hablar de una tipología muy concreta de personajes: los invisibles. En este sentido, me gustaría señalar aún un uso más de la construcción verbal de elementos dramáticos, que tiene que ver, en este caso, con la mención de personajes que nunca aparecen en escena, pero desempeñan un papel en la obra, a veces fundamental, por el poder que ejercen sobre el resto y por la inflexión que producen en la acción ${ }^{15}$. Aunque este sea un recurso usado en el teatro posterior, no deja de ser por ello un ejemplo de economía dramática puesta al servicio de la representación.

Entre las obras del Códice analizadas, hemos encontrado algunos casos muy significativos que paso a comentar a continuación: en el Auto del destierro de Agar, Sara, exige a Abraham que expulse a su esclava y concubina Agar, junto a Ismael, el hijo que tuvo con ella, para que este no le usurpe la sucesión a su propio vástago Isaac. Aunque la artífice sea Sara, el detonante es el joven Isaac, quien no aparece en el elenco inicial, pues no es un personaje al que los espectadores vean en escena. Sin embargo, su presencia es tan real como las cuatro ocasiones en las que se le menciona. El carácter de las alusiones que de él se hacen depende de quien las emita: su madre, a través de la voz interpuesta del narrador de la loa, dice que fue maltratado por Ismael (v. 32) y reivindica que es el heredero (v. 37); su padre, Abraham, lo menciona como «nuestro Isaac tan querido» (v. 92); el ángel afirma: «Dios tiene elegido / a tu Ysaac por heredero" (144); por último, a través de un pastor sabemos de su condición infantil: "Ysaac es niño» (v. 171). Con estas deixis el público construye una proyección muy real, apoyada por su conocimiento previo de la historia sagrada, que dramáticamente confiere a Isaac un valor actancial ${ }^{16}$ marcado de rasgos positivos, aunque esto vaya en detrimento de Ismael y su madre.

De manera muy similar, pues de otro conflicto fraternal se trata también en este caso, aunque con un enfoque radicalmente distinto, se dibuja verbalmente a Esaú, en el Auto de cuando Jacob fue huyendo a tierras de Arán. Dado que no es un personaje visible, de nuevo está ausente del elenco de figuras, pero el protagonista en su primera aparición agradece a Dios lo siguiente:

Jacob: Sacásteme de Israel,

librásteme de la mano

sanguinolenta cruel

dramáticas y alegóricas en los autos de Calderón, Reichenberger-Universidad de Navarra, KasselPamplona, 2001, p. 150.

14. Véase su artículo: «Tipología de los personajes hermosos en el Códice de Autos Viejos», Criticón, nos. 94-95, 2005, pp. 147-168.

15. Aland Deyermond realizó un análisis sobre La Celestina, que, salvando las distancias genéricas, me ha servido de referente. Véase: «¿Cuántas hermanas tenía Celestina? La función de los personajes invisibles», Medievalia, no 40, 2008, pp. 96-104.

16. Que podría situarse como objeto (en la clasificación de Greimas) o de destinatario del bien (Soriau), si atendemos a la tradición cristiana, que le da prioridad sobre Ismael. 
Ya en presencia de su tío Labán, en cuyas tierras va a refugiarse, relata que su madre Rebeca, al ver que Isaac iba a darle prioridad a Esaú, le animó a que llevase un regalo a su padre, quien, gracias a tal ofrenda, le bendijo a él. En una segunda deixis ad phantasma dice Jacob:

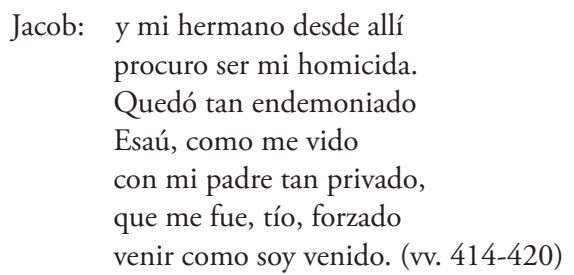

Previamente, en la loa (vv. 44-45), ya se nos había presentado a Esaú como el causante de la huida de su hermano, por lo que, de nuevo, el espectador habrá dado una entidad actancial a ese personaje, quien se ha convertido claramente en el oponente, aun cuando no ha pasado por el escenario.

El tercer caso de invisibilidad que quería presentar se da en El auto del rey Asuero cuando ahorcó a Amán, donde Mardoqueo se convierte en un ente clave, desde que Amán le dedica, en el primer parlamento tras la loa, más de sesenta versos, para justificar la venganza que le tiene preparada a él y a su pueblo. Recojo los primeros versos aderezados de calificativos, que culminan con un comentario alusivo a la raza, que parece avanzarnos los sonidos de un teatro posterior donde el ataque a los judíos se convertirá en un tópico:

Amán: Muy cautamente he guiado

la venganza a mi deseo.

Huelgue agora Mardoqueo,

y esté en sus trece obstinado

el vil, bajo y torpe hebreo. (vv. 61-66)

Como en ocasiones anteriores, el tono del retrato verbal del personaje depende de quien lo realice y la intención que ponga a sus palabras. Pocos versos después será Atac, un criado de Ester, quien ofrezca una imagen lamentable de un Mardoqueo vencido por la desesperación:

Atac: Sobre una piedra sentado le topé, mirando al cielo, pensativo, trashijado, mal vestido, desgreńado, a pura planta en el suelo; una color como muerto, con un silicio vestido, a golpes el pecho abierto, todo el cabello cubierto de ceniza, y sin sentido; y cuando me vio presente comenzó a echar maravillas 
de aquella boca prudente, siendo arroyo sus mejillas, sus ojos, manantial fuente. (vv. 142-156)

Amán usa el término despectivo de «vejezuelo apocado» (v. 311), cuando ya saborea su venganza. Ester alude a él como «el pobre viejo» (v. 360) para ganarse la benevolencia de Asuero. Aunque el público se haya construido una imagen de víctima, Mardoqueo ha sido el auténtico Deus ex machina, un ayudante clave, en los sucesos del auto. A pesar de su invisibilidad, como si de una voz en off se tratara, consigue que sus palabras sean oídas en el escenario, transmitidas literalmente por Atac a Ester, en quien provocan la anagnórisis necesaria para cambiar el desenlace:

$\begin{array}{ll}\text { Atac: } & \text { «Oh la mas impía mujer } \\ & \text { de cuantas crio natura!», } \\ & \text { dijo. «¿Posible es qu'Ester, } \\ & \text { viendo tal, no se aventura? } \\ & \text { Entre, que no ay que temer; } \\ & \text { que si la mandare el rey } \\ & \text { matar, fama esclarecida } \\ & \text { habrá. Quebrante la ley, } \\ & \text { qu'el morir es cobrar vida, } \\ & \text { feneciendo por su grey.» (vv. 182-191) }\end{array}$

El último fantasma que quiero mencionar es Amón, cabeza visible de la tribu que lleva su nombre, quien protagoniza el enfrentamiento con Jefté, en el Auto del sacrificio de Jeté. Sucesivas deixis construyen un doble personaje invisible: por un lado encontramos un ente colectivo, al que se denomina hijos de Amón (vv. 141, 169, 279) o príncipes de Amón (v. 204) y se dice de ellos que se muestran muy guerreros (v. 205):

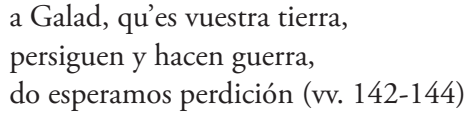

Serán el ejército al que venza el protagonista; aunque no veremos uno solo de estos soldados en escena, ya que las batallas y la victoria, en un ejercicio de economía dramática, las conoceremos a través de la narración de los correos. En segundo término, se perfilará al propio Amón, el antagonista, mediante su negativa a la invitación de Jefté a deponer su ataque a los de Galaad. Un emisario transmite, en estilo indirecto, sus palabras, lo que desencadena la guerra.

Los ejemplos recogidos parecen constituir un conjunto de personajes o figuras actanciales que desempeñan una función importante, como detonantes o antagonistas de la acción, y cuya existencia reside en la capacidad de los espectadores para reconstruirlos a partir de las palabras de uno o varios personajes o de las suyas propias pronunciadas por persona interpuesta. No sé si puede hablarse de una tipología, pero sí de un recurso verbal más que contribuye a la construcción dramática de forma efectiva. 
Tanto en el caso del relato de sucesos como en el de los personajes invisibles, la balanza parece inclinarse hacia lo auditivo frente a lo visual, en consonancia con ese carácter más narrativo que se le reconoce al Códice. Sin embargo, he dejado para el final una tipología de personajes que apuntan en la otra dirección. Se trata de los personajes silentes, cuya presencia parece tener la misma funcionalidad que la de cualquier otro elemento u objeto del atrezo. Son frecuentes las obras en las que el elenco nos arroja un número importante de actores en escena, a los cuales no siempre se les da voz o permanecen semiidentificados por denominaciones genéricas, que no permiten siquiera saber cuántos y cuáles de los denominados intervienen en cada caso. Un buen ejemplo lo encontramos en el Auto de la entrada de Cristo en Jerusalem, donde, de los «doce apóstoles» $\mathrm{y}$ «tres fariseos» del elenco, solo se da voz a uno de cada grupo sin poder determinar si siempre es el mismo ${ }^{17}$. Mercedes de los Reyes distingue entre personajes genéricos - músicos, soldados, pastores, ladrones, etc.- y aquellos que pertenecen a la categoría de histórico-bíblicos, en la que incluye a los Apóstoles ${ }^{18}$. Tal diferenciación resulta útil para lo que quiero explicar, pues, si bien la inclusión de personajes colectivos, que pueden incluso carecer de texto, responde a un intento de enriquecer la escena desde un punto de vista visual y escenográfico, en el caso de aquellos que son localizables en la historia bíblica debemos presuponer además una segunda intención didáctica. La mera presencia en bloque de todos o casi todos los discípulos, motivo recurrente en varios de los autos neotestamentarios (las dos versiones del Aucto de la asuncion de Nuestra Señora, Auto de la entrada de Xpo en Jerusalen, Auto del hospedamiento que hizo sancta Marta a Christo, Auto de la asumptión de Nuestra Señora y Aucto de la conversión de la Madalena), dejaba seguro un impronta de unidad y hermandad en la retina de los espectadores, a la que habría que sumar alguna otra función como la de actuar como receptores intermedios de un mensaje evangelizador, dirigido en última instancia a los espectadores. Véase el siguiente pasaje de La entrada de Cristo en Jerusalem:

\author{
Cristo: Mis discípulos y hermanos, \\ tomad en esto lición, \\ y huid de la estimación \\ de los estados mundanos. (vv. 364-367)
}

De igual forma, los dos autos que recogen momentos clave en la infancia de Jesús cuentan con la presencia del niño como personaje necesariamente silencioso - de nuevo ausente del elenco-, pero con una entidad simbólica fuera de toda duda. Tanto en el Aucto de la circuncisión de Nuestro Señor como en el Auto de la huida de Egipto, varias intervenciones de la Virgen y de San José evidencian la necesidad de que haya un bebé -aunque probablemente no de carne y hueso- en el escenario, a quien dirigir los angustiados lamentos de

17. Además de la «Turba del pueblo», que también aparece como personaje colectivo en cada intervención, pero que, a diferencia de los anteriores, es de suponer integrada por varias personas que hablan todas a la vez.

18. Op. cit., pp. 912-913. 
los progenitores por el sufrimiento al que va a ser sometido, como evidente trasunto de la pasión:

$\begin{aligned} \text { Na Señora: } & \text { ¡Oh riqueza y alegría } \\ & \text { del cielo ya fabricado, } \\ & \text { redención del alma mía! } \\ & \text { De veros, hijo, temblar } \\ & \text { siento yo penas estrañas, } \\ & \text { y en la sangre contemplar } \\ & \text { que hoy habés de derramar } \\ & \text { se me abrasan las entrańas. (vv. 103-110) }\end{aligned}$

Esta imbricación entre la intención o contenido del texto, el manejo de los recursos dramáticos y su repercusión sobre el público se hace aún más patente en los casos que quiero comentar a continuación. Dos piezas presentan escenas similares con una funcionalidad parecida: en el Auto del finamiento de Jacob, le acompañan en el lecho de muerte su hijo José con sus dos vástagos, Efraín y Maneses, que no aparecen en el elenco inicial de «figuras», suponemos que porque no pronuncian texto alguno. Sin embargo, su presencia materializa visualmente el sentido de la escena: la consolidación de la genealogía de Jacob en sus descendientes, a través de su última bendición. El autor de la pieza no se limita a hacerlos entrar sino que organiza en torno a ellos un movimiento escénico cargado de simbología: en primer lugar, Jacob no permite que se retiren a un segundo plano sino que pide explícitamente que se mantengan cerca. En segundo término, José, en un ejemplo de acotación implícita, dice:

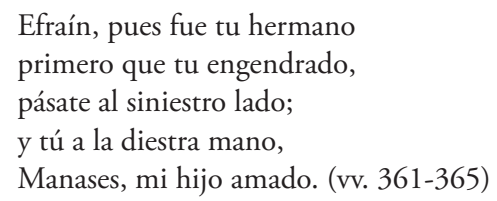

A pesar de lo cual, en una tercera y sucesiva indicación escénica, cuando Jacob les bendice, coloca su mano derecha sobre Efraín. José le advierte del error de este movimiento, a lo que el padre contesta que es la voluntad de Dios que «qu'el mayor menor será» (v. 390).

La prelación de uno de los vástagos es también el motivo central de El auto de la ungión de David, donde de nuevo se organiza todo el movimiento de la escena principal en tono a las figuras de los hijos de Ysay, entre los que está el elegido. En este caso sí aparecen en el reparto inicial como «hijos», pero todos permanecen mudos a excepción de David, a quien significativamente se menciona aparte en el elenco. Como si de una verdadera coreografía se tratase, Samuel va ordenando a Ysay que los vaya llamando sucesivamente para que deambulen por delante del altar del sacrificio, mientras Dios los rechaza uno a uno. Solamente se da voz a uno de ellos, indeterminado, cuando su padre le envía en busca del menor: David. Cuando llega, Samuel y él se postran ante el altar, y una doble acotación implícita (v. 411) y explícita (tras el v. 415) señala que de rodillas es ungido el elegido. La aportación escénica del resto de los 
hijos silentes ha tenido el efecto simbólico de resaltar la figura de David y la inexorabilidad de los designios de Dios.

El último personaje al que quiero hacer referencia me lleva a la tipología femenina y nos acerca a una pieza que tiene como motivo central la justicia y como detonante a una figura cuyo nombre proviene de ese campo léxico: me estoy refiriendo al Auto del robo de Dina. En este caso la protagonista femenina no es completamente muda, tiene voz en la escena inicial (v. 31-120), en la cual se produce su rapto por parte del príncipe Siquen. A partir de ese momento se suceden las desgracias desencadenadas por la supuesta provocación de Dina y la ofensa de Siquen, vengada a traición por los hermanos de la joven. A Dina no se le vuelve a dar un solo parlamento y las acotaciones no señalan su presencia. Sin embargo, al final de la obra, cuando su padre conoce las devastadoras consecuencias de la acción de sus hijos, culpa de todo a Dina, cuya falta ha consistido en su deseo de socializar, expresado en el texto con las siguientes palabras: «quiero llegarme a Salen / a mirar y ser mirada.» (p. 50). En la escena final, sabemos que Dina vuelve a estar en el escenario por las propias palabras de Jacob, quien, curiosamente, la manda callar cuando, como he dicho, no hay ningún indicio de su presencia:

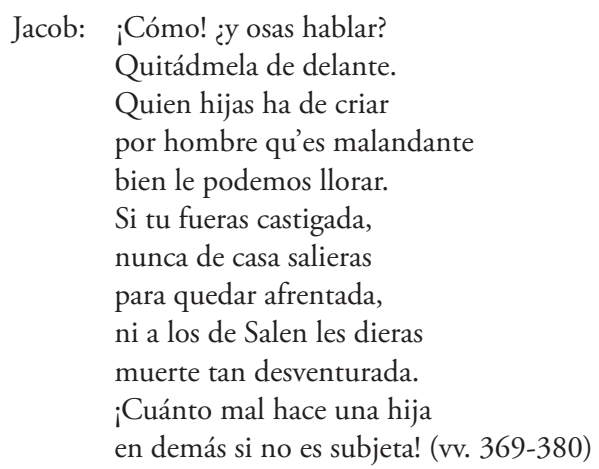

El autor ha querido volver a sacarla a escena para que el público tenga ante sus ojos al personaje sobre el que recae la responsabilidad, es decir para reforzar visualmente el mensaje verbal, de carácter didáctico:

\author{
¡Oh padres en mi tomad \\ gran escarmiento y consejo: \\ vuestras hijas castigad, \\ y mirad qu'es aparejo \\ de su mal la libertad! (vv. 384-388)
}

El silencio, en este caso, implica la asunción de la culpa y el predominio de la voz masculina: es evidente en el Antiguo Testamento la función que las hijas de Eva suelen asumir, después de aquella primera intervención femenina. En estas páginas las hemos visto también, es el caso de Rebeca (que provocó la ventaja de Jacob sobre Esaú) o de Sara (que exige a Abraham que expulse a Agar e Ismael, después de que ella fue quien animó a su marido a tener un hijo con la esclava), como incitadoras de las acciones masculinas. 
Para concluir, en el análisis que he realizado en estas páginas se puede observar un predominio del carácter narrativo de las obras del Códice que desempeña funciones múltiples, como son: explicar la prehistoria o adelantar sucesos, suplir otros recursos dramáticos estructurales o contextualizadores, hacer explícitas las relaciones comunicativas en escena, ofrecer reiteraciones didácticas o moralizantes, entre otras. En este sentido he querido detenerme un poco más en un último uso de la proyección verbal, que exige la participación activa del espectador para que elabore una realidad virtual que dé vida a los personajes invisibles. A pesar de que su materialización en la mente del espectador siga respondiendo a un uso de la narratividad, encontramos en este recurso un interesante ejemplo de economía dramática, utilizada por los autores con mucha osadía, pues confían en que el receptor sea capaz de reconstruir un personaje con un peso importante en el desarrollo de la acción. Suelen ser deixis ad phantasma que, simbólicamente, representan a los personajes motivantes o a los antagonistas en la sombra. Por último, he querido apreciar otro esfuerzo más de los autores de estas obras en su intento de inclinar esa balanza de la que hablaba al inicio hacia lo visual, mediante la utilización de personajes silentes, con una función dramática que vas allá de lo ornamental y muestra una cierta preocupación por el movimiento escénico y la simbología de todos los elementos que el espectador puede contemplar. ¿¿Suponen estas obras un avance en la madurez de la creación teatral, respecto a las eminentemente narrativas, que pudiera ayudarnos a establecer una prelación cronológica? Quizás sea demasiado arriesgado aventurarse en esta dirección, pero creo que sí podemos vislumbrar en los autores de estas piezas una cierta reflexión sobre la creación dramática, y los recursos que la vinculan o la alejan del género narrativo.

\section{Obras del Códice de Autos Viejos utilizadas para el estudio ${ }^{\text {I9 }}$}

1-Auto del sacreficio de Abraham (I), t. I, pp. 1-21.

2-Aucto del destierro de Agar (II), t. I, pp. 22-34.

3-Aucto de cuando Abrahan se fue a tierra de Canaán (III), t. I, pp. 35-50.

4-Aucto de cuando Jacob fue huyendo a tierras de Arán (IV), t. I, pp. 51-66.

5-Auto de los desposorios de Ysac (V), t. I, pp. 67-96.

6-Aucto de los desposorios de Isac (VI), t. I, pp. 97-115.

7-Auto del robo de Digna (VIII), t. I, pp. 136-151.

8-Aucto del Magna (X), t. I, pp. 169-181.

9-Aucto de la lucha de Jacob con el ángel (XI), t. I, pp. 182-199.

10-Aucto del finamiento de Jacob (XII), t. I, pp. 200-216.

11-Auto de Sansón (XIII), t. I, pp. 217-231.

12-Aucto del rey Nabucdonosor quando se hizo adorar (XIV), t. I, pp. 232251.

19. Mantengo el orden, la numeración y la paginación, así como la ortografía, de la edición de Rouanet. 
13-Auto del sueño de Nabucodonosor (XV), t. I, pp. 254-266.

14-Aucto del rey Asuero quando desconpuso a Basti (XVI), t. I, pp. 267-282.

15-Auto del rey Assuero quando ahorco a Amán (XVII), t. I, pp. 283-300.

16-Aucto de la lepra de Naamán (XVIII), t. I, pp. 301-314.

17-Auto de la ungión de David (XIX), t. I, pp. 315-330.

18-Auto de los desposorios de Joseph (XX), t. I, pp. 331-357.

19-Aucto de Tobias (XXI), t. I, pp. 358-376.

20-Aucto de Abrahán quando vençió los quatro reyes (XXII), t. I, pp. 377-393.

21-Auto del sacrificio de Jeté (XXIV), t. I, pp. 408-425.

22-Aucto de la conversión de Sant Pablo (XXV), t. I, pp. 426-436.

23-Aucto de la asunción de Nuestra Señora (XXXI), t. II, pp. 1-7.

24-Aucto de la asunción de Nuestra Señora (XXXII), t. II, pp. 8-20.

25-Aucto de la degollación de sant Juan Baptista (XXXV), t. II, pp. 48-61.

26-Auto de la muerte de Adonías (XXXVI), t. II, pp. 62-77.

27-Aucto del peccado de Adán (XL), t. II, pp. 133-149.

28-Auto de Cain y Abel (XLI), t. II, pp. 150-166.

29-Aucto de la prevaricación de nuestro padre Adán (XLII), t. II, pp. 167-185.

30-Auto de la entrada de Xpo en Jerusalén (XLVI), t. II, pp. 264-278.

31-Aucto de la prisión de sant Pedro (XLVII), t. II, pp. 279-293.

32-Aucto del hijo pródigo (XLVIII), t. II, pp. 294-313.

33-Auto de los desposorios de Moysén (XLIX), t. II, pp. 314-329, en prosa.

34-Aucto de la circuncisión de Nuestro Señor (LI), t. II, pp. 356-373.

35-Auto de la huida a Egipto (LII), t. II, pp. 374-387.

36-Auto del despedimiento de Christo de su madre (LIV), t. II, pp. 403-420.

37-Auto del hospedamiento que hizo sancta Marta a Christo (LVI), t. II, pp. 438-448.

38-Aucto de Nabal y Anigail y David (LIX), t. II, pp. 502-513.

39-Auto de la resurrección de Christo (LXI), t. II, pp. 514-542;

40-Auto de la resurrección de Christo (LXI), t. III, pp. 1-18.

41-Auto de la asumptión de Nuestra Señora (LXII), t. III, pp. 19-33.

42-Aucto de la conversión de sant Pablo (LXIII), t. III, pp. 34-48.

43-Aucto de la conversión de la Madalena (LXIV), t. III, pp. 49-66.

44-Auto (sin título, incompleto) (LXVII) [con Abigail y Rachel], t. III, pp. 121-130.

45-Aucto del descendimiento de la Cruz (XCIII), t. IV, pp. 29-46.

46-Aucto de la resurrección de Nuestro Señor (XCV), t. IV, pp. 66-104.

47-Aucto de la paciencia de Job (XCVI), t. III, pp. 105-127. 